\title{
EMIGRACIÓN Y CONTINUIDAD CULTURAL DE LOS WIXARITARI. BREVE REFLEXIÓN SOBRE UNA RELACIÓN AMBIGUA
}

\author{
María Florentine Beimborn \\ Alberto Romandía Peñaflor
}

\begin{abstract}
Resumen: El pueblo wixarika ha estado siempre en contacto con sus alrededores, especialmente entablado mediante el entrelazamiento de prácticas comerciales, de la migración laboral y la peregrinación. Sostenemos, basados en investigaciones habidas y en ejemplos empíricos, que la persistencia de la cultura y comunidad wixarika debe ser explicada a través de procesos de identificación de cara al otro y a la creativa integración de lo ajeno. Enfocando a los emigrantes-peregrinos, observamos prácticas de cómo lo propio y lo ajeno confluyen en «mundos de la vida». En vez de ir «othering» a los emigrantes y cuestionando la autenticidad de sus identidades étnicas y prácticas culturales, magnificamos su papel crucial en el engrandecimiento de la continuidad cultural.
\end{abstract}

Palabras clave: pueblo wixarika, emigración, continuidad cultural, de-y reterritorialización, vida ritual, bricolaje cultural.

Enviado a dictamen:12 de agosto de 2009

Aprobación: 29 de septiembre de 2009

Revisiones: 1

María Florentine Beimborn, pasante de la Maestría (Magister) en etnología y sociología por la Eberhard-Karls Universität Tübingen, Alemania, temas de especialización: fenómenos de la glocalización, etnología urbana, seguridad social, Mesoamérica, Asia del sur. Correo electrónico: mariabeimborn@hotmail.com.

Alberto Romandía Peñaflor, licenciado en filosofía por la Universidad de Guadalajara, temas de especialización: labor social, mexicanidad, teología, arte y cultura. Correo electrónico: alverkokotl@yahoo.com.mx.
Abstract: The wixarika people have always been in close contact with their closer and further surroundings, especially initiated through the interlocking practices of commerce, work-migration and pilgrimage. We argue at the base of given researches and some own empirical examples that the persistence of wixarika culture and community should be explained through the identification face to face with the other and the creative integration of the foreign. Focusing migrant-pilgrims we observe practices of how the own and the foreign is merged in»life-worlds «. Instead of »othering « the migrants and questioning the authenticity of their ethnic identities and cultural practices we acclaim their crucial role for the enormous cultural continuity.

Key words: wixarika folk, migration, cultural continuity, de-and reterritorialization, ritual life, cultural bricolage.

\section{Introducción}

$\mathrm{P}$ odría decirse sin lugar a equivocación que casi cada familia wixarika (en español huichola) se ve directamente afectada por la migración. Algunas estimaciones hablan de diez mil emigrantes serranos (Weigand, 1992), otras cifras menos entusiastas se aproximan a los veinte mil (Rojas, 1993: 199); lo que representa la mitad de la etnia (censo CDI, 2000). ${ }^{1}$ La emigración no es un fenómeno nuevo entre la comuni- 
dad wixarika, sino que tiene ya una historia de más de quinientos años. Luego, nos resulta grave, trascendente, y de más, significativo, discutir ese aspecto de la cultura huichola, el cual se ve caracterizado por una impresionante continuidad sociocultural en relación íntima con el fenómeno del éxodo de la Sierra Madre o Huichola. En lugar de tratar la migración como epifenómeno (periférico o accesorio) de la cultura, la historicidad y la persistencia, queremos discutir que aquélla, entre otras formas de contacto con el otro - como comercio, peregrinación, sincretismo, mímesis y aculturación - juega un papel central para la "supervivencia" de semejante cultura, así como en la justificación de prácticas de resistencia en este grupo étnico; si bien en el peor de los finales pareciera que tal pueblo podría prescindir del contacto con los otros, siempre y cuando no se extinga su divina trinidad: ikú, marra y híkuri; en torno a los procesos de reproducción cultural y migración en el siglo XXI, hemos omitido profundizar la discusión con los estudios especializados en la emigración per se como tema adyacente, dado que ello orientaría la investigación aquí propuesta en el sentido más amplio del que nos hemos circunscrito a esbozar: la migración huichola. En fin, habremos de mostrar, en base al estudio de la etnohistoria que se centra en este tema, y partiendo de algunas entrevistas informales con huicholes sobre diferentes experiencias de emigración (con los cuales convivimos en la costa y sierra nayarita, en San Andrés Cohamiata, San Sebastián Teponahuaxtlán, Guadalajara y Puebla), que la migración juega un papel de primer orden en tal cultura, así como en la vida social del huichol; entre tantos otros aspectos: por una parte, a razón de las diversas dinámicas entre emigrantes y las comunidades de la sierra; y por otra, debido a ser ésta una arena esencial y rica de distintas prácticas y reflexiones de la Id-entidad wixarika en un mundo globalizado "entre paréntesis".

La primera sección de esta investigación cualitativa presenta e identifica la historia de la migración huichola y los distintos tipos de emigrantes que provocaron las variadas condiciones sociohistóricas del contexto. En dicha sección, vamos a acotar la relación entre las rutas prehispánicas de comercio, la cual no sólo coincide con la de las rutas de peregrinaciones sino que también representa las principales vías de emigración de la etnia en cuestión. En la segunda sección, presentaremos algunas experiencias de los emigrantes huicholes actuales, así como su representación en autorretratos (Ramón Medina Silva, "Mad Jesus"). ${ }^{2}$ Luego, en la tercera y más extensa sección se discute la relación entre emigración y la continuidad y resistencia de la cultura wixarika. Bajo este enfoque serán discutidas, sobre todo, las prácticas de dos grupos de emigrantes, que en lugar de "perder" su cultura, se preocupan por su continuación y si no devienen más huicholes fuera de la sierra, sí alimentan su cultura. El primer grupo del que hablaremos halla su núcleo en refugiados que se han organizado en comunidades tradicionales alrededor del Río Lerma, del Santiago, en Nayarit y en Tepic. El segundo artífice o auspicio de esta reflexión tiene sus fueros en los así llamados "Huicholes urbanos". El tercer bloque de la sección va a enfatizar la relación entre emigración y reproducción cultural, especialmente con incidencia a la relación: migración=vida ritual.

Así, vamos a analizar una idea referencial, a saber, cómo es que la emigración/ la movilidad, en lugar de ser un tema adyacente con respecto a la cultura wixarika y su continuidad, debe ser tratado como una parte constitutiva de dicho pueblo. Y ello no sólo a razón de que el capital llevado a la sierra apoya en gran medida la continuación de la vida "tradicional" en aquellas latitudes; por decirlo así, es en el corazón de la cultura donde se reproduce. Más aún, porque la migración es un fenómeno tan común entre grupos huicholes desde hace tiempo. Por lo mismo, es una arista digna de acentuar en la realidad del ser huichol, tanto como lo son los rituales y su cosmogonía, los mitos, la vida comunitaria y las peregrinaciones. (Habría que conformar otro espacio donde apurar el análisis de algunos vicios y abusos psicosociales en indígenas y mestizos; dejamos 
tal labor a los entendidos). Ahora bien, integrar el tema de la emigración en los estudios sobre los wixaritari y demás pueblos indígenas, permite entender en mayor perspectiva las dinámicas de la cultura huichola y en general de la posmesoamericana, dada la posibilidad de visión puntual sobre cómo se reproduce la cultura en intensiva interacción con "el otro". En lugar de entender a los huicholes como sobrevivientes en lejanas montañas aisladas, vemos una imagen de ellos como actores en varias arenas, quienes activamente reproducen su cultura y reafirman su identidad étnica per se, así como en contacto con el mundo globalizado.

\section{Planteamiento histórico y tipos de la emigración wixarika}

La temprana imagen antropológica de los huicholes culturalmente aislados ya ha sido superada, si bien sigue teniendo importancia/vigencia la atávica hipótesis en el sentido geográfico. Hoy poseemos conocimientos históricos que prueban un contacto constante con otros grupos étnicos desde tiempos prehispánicos. Allan Franz, en vez de explicar la continuidad cultural por el aislamiento, presenta otro enfoque al argumentar que,

la fuerza y cohesión del sistema sociocultural huichol existe a pesar - o en un sentido a causa - de sus interrelaciones con otros grupos indígenas como inmigrantes; debido a su etnohistoricidad cual grupo discreto, está inextrincablemente vinculado con la historia interna del México occidental (Franz, 1996: 63).

Tal autor ofrece una respuesta histórica a la pregunta de la continuidad de la cultura huichola en diálogo con el otro. Como muestra Weigand (1992), existe una coincidencia entre varias rutas prehispánicas de comercio y rutas de peregrinaciones. El comercio de la sal se encontró con la visita a la diosa del mar - Haramaracerca de San Blas, y en la sierra de San Luis Potosí no sólo se encontraba la sagrada tierra de los dioses y el origen del cosmos —Wirikuta - sino también el muy traficado cactus de peyote - Híkuri- Entonces, desde hace un cúmulo incalculable de años las miríadas de peregrinaciones cíclicas han servido a los huicholes para tener nociones sobre el otro y darse a conocer por él, a la par de las actividades económicas que dicho contacto ha implicado. Estos trayectos de peregrinaciones cíclicas y del comercio representan las más frecuentadas rutas de emigración huichola (Neurath, 2002: 2l y 79). Cuando por décadas los huicholes se fueron de la sierra para vender su mano de obra (sea en las minas de Zacatecas o San Luis Potosí, en los campos de la costa pacífica, o en los mercados de Guadalajara) se movían ya en terra cognita, en su territorio sagrada (Figura l).

Supone Neurath, que en tiempos prehispánicos ya había emigrantes huicholes, ante todo peregrinos, quienes se vieron impelidos, justamente por esa condición itinerante, a negociar durante su estancia fuera de la sierra. Desde el siglo XVI hay registros de huicholes trabajando como asalariados en las minas de Zacatecas y en los campos agrícolas mantenidos por los Españoles, aún cuando el impacto del sistema hispano en la sierra se haría esperar hasta el siglo XVIII (Franz, 1996: 69), y esto a través de los franciscanos. Actualmente, podemos identificar un primer tipo de emigrantes que practican la salida o emigración estacional o golondrina: trabajan como obreros y empleados fuera de la sierra en la estación seca y regresan al final de la temporada. Cuando antes, la temporada eventual era relativa y claramente limitada, muchos de los emigrantes estaciónales retornaban a comienzos de otoño para cultivar sus tierras en la sierra (Neurath, 2002: 293). En nuestros aciagos tiempos, se están ampliando, todavía más, las posibilidades de trabajo agrícola asalariado para la siembra de diferentes frutos durante distintas temporadas y, de este modo, muchos huicholes pasan de un trabajo a otro sin regularmente regresar a la sierra. La emigración estacional tiene sus raíces en el siglo XVI, si no es que antes, y se extendió geográficamente por la ingente cantidad requerida de mano de obra, cuyo auge se vio colmado con el paso de los siglos. Mientras que 
antes, la labor englobaba apenas a la zona potosina, hoy una gran porción de los empelados huicholes trabaja en la región cerca de la costa de Nayarit en los campos de tabaco, maíz, caña, horticultura y café, y del mismo modo otros van hasta los campos en el sur de Jalisco, Sinaloa, Zacatecas y Aguascalientes.

Los impactos de las guerras de independencia, revolución mexicana, y más aún la revuelta cristera, provocaron un segundo tipo de inmigración: los refugiados. Debido a presiones de los mestizos en el territorio huichol y también a causa de la violencia por parte de los rebeldes irrumpiendo en las comunidades de la sierra, mucha gente huyó de las montañas hacia la costa, donde grupúsculos se establecieron definitivamente tanto en comunidades indígenas como en pueblos mestizos (Río Lerma de Santiago, Zoquipan, Colorado de la Mora, etcétera). Factores como: la escasez de tierra para actividades agrícolas, el olvido social, la falta de conocimientos básicos, la agresiva coacción y el continuo chantaje por parte de los rancheros mestizos hacia la sierra, sigue orillando a familias enteras de estas comunidades a emigrar. Pues prefieren poner sus pies en polvorosa y buscarse un destino allende su territorio.

Un tercer tipo de emigración debe tener sus raíces a principios del siglo XX, cuyo apogeo aún hoy día es de verse en todo el país: la emigración de artesanos (Figura 2).

No hemos encontrado investigación alguna que estudie a fondo sobre los principios de la mencionada nueva generación de emigrantes. Lo que sí se puede predicar y resulta más que obviado, es que a causa de los primeros antropólogos que investigaron las culturas del Gran Nayar y su especial interés por la cultura material, así como por exigencias del turismo nacional e internacional escarpado en el siglo XX, la demanda por adquisición de bienes exóticos aumentó de modo exacerbado. Cuando en un principio pareció haber sido una actividad adicional de los inmigrantes obreros, el empleo de artesanía devino en producción económica y se desarrolló como uno de los másimportantesingresos para muchas familias huicholas tanto en la sierra como fuera de ella (Knab, 2004: 149).
La artesanía, por supuesto, es una actividad muy importante. Los productos se elaboran en parte para satisfacer necesidades propias, pero muchos objetos -frecuentemente de menor calidad artística - se fabrican ex profeso para venderlos a los teiwarixi. La venta se puede realizar en la misma sierra, pero normalmente se emprenden viajes a los centros urbanos y turísticos del occidente, centro, norte y sureste de la República. Muchos artesanos huicholes han emigrado definitivamente de la sierra, pero aún mantienen ciertos vínculos y regresan ocasionalmente a sus ranchos o comunidades de origen (Neurath, 2002: 131). ${ }^{3}$

Por el momento, cabe mencionar que la actividad económica de la producción y venta de artesanías tiene una gran influencia en la cultura huichola, tanto en los diseños, como con respecto a su dimensión económica, más ello se discute en otro lugar del trabajo.

Como último tipo de emigración habremos de presentar a los curanderos comerciales. Esta forma de emigración tampoco es un fenómeno nuevo. Ya Lumholtz, a fines del siglo XIX, observaba que varios chamanes huicholes - Mara'akate - aparecían entre los otros grupos indígenas del Gran Nayar, junto a Coras y tepehuanes (del sur, norte, tepecanos, etcétera) (Lumholtz, 1904: cap. XXVII). Hoy encontramos a chamanes huicholes vendiendo su servicio no sólo a gente de otras etnias en la sierra, sino también, su gran éxito, con clientela mestiza e internacional en México y los Estados Unidos (Neurath, 2002: 132) y aún en Europa y Asia (Figura 3).

Entre los tuapuritari hay varios mara' akate itinerantes que cantan para los Tepehuanes, que les pagan mucho mejor que los Huicholes. Los mismos chamanes profesionales curan a mestizos rurales supersticiosos o urbanos de clase media inspirados por el denominado new age. La curandería comercial es una actividad que sólo se desarrolla fuera de la comunidad, mientras que el trato entre chamanes y comuneros tiene que 
ser diferente. A un maráakame no se le paga más de lo justo, pues no se permite lucrar con las costumbres (Neurath, 2002: 131). ${ }^{4}$

Siendo así, hemos aislado cuatro tipos de emigrantes, los cuales representan paradigmas ideales que encontramos flexiblemente mezclados en el mundo empírico (véase para ejemplificar a Furst, 2002: 185; y Knab, 2004: 149). Vimos ya, que cada tipo de éstos se halla en relación íntima con un momento histórico de sus condiciones tanto en relación con la comunidad wixarika, como con la sociedad mestiza. Los motivos para la emigración, sea ésta temporal o definitiva, parecen ser una combinación entre necesidades e intereses económicos, y también del hábito de trasladarse, de circular por el mundo. Debido a las peregrinaciones (como costumbre), que son practicadas por un gran número de los huicholes, moverse por el mundo se descubre como una tradición. Para el caso específico de los huicholes, esta capacidad de transitar geográficamente desde siempre ha concordado con fines económicos.

\section{Recuerdos y experiencias de emigrantes}

Sobrevivir al trabajo en el campo, al de la artesanía o la curandería no es fácil. Pues, aunque la mano de obra es requerida, y la artesanía es apreciada y se va posicionando; así como la curandería huichola es mistificada tanto por la sociedad mestiza como por los turistas, su paga y trato justos son relativamente escasos, siendo el costo de vida, con relación a dentro de la sierra, alto. El wixarika no sólo tiene que pagar por un lugar donde dormir (bien que muchos comparten la casa entre varios miembros), por alimentación y sustento, sino que también por el material y la transportación, desde y hasta la sierra, y hacia los diferentes lugares donde venden sus servicios y productos.

La experiencia del trabajo campesino (agrícola) es dura y son enormes los efectos a la salud por los químicos usados en la agricultura (Furst/Schaefer, 1996: 514).
Descendí a la costa en Nayarit (...) a trabajar en la cosecha de maíz. Muchos huicholes, muchos, muchos, van ahí cuando están hambrientos. Cada año se van, dejan la sierra y bajan a la costa, para ganarse unos cuantos centavos en los campos de maíz, en los campos de tabaco. Luego retornan, pobres, con enfermedades, otros agotados, hechos polvo (Medina, 1996: 189).

Es evidente que los artesanos y curanderos no se encuentran en una mejor condición (pocos tienen posiciones bien holgadas, y aún existen entre ellos adinerados comerciantes). Están en constante búsqueda de clientes y espacios, aunque hay varias tiendas y organizaciones que les apoyan (por ejemplo la misión de Zapopan y tiendas en los centros turísticos alrededor de las costas de Nayarit y Puerto Vallarta, etcétera).

Hay huicholes que emigran con sus familias y otros que van solos. Cuando las familias parecen tender a establecerse en algún sitio, los que viajan solos circulan mucho, y no sólo entre diferentes lugares donde encuentran trabajo o clientes sino también entre la sierra y fuera de ella. En 2007 conocimos a un huichol quien vive cerca de San Blas. Emigró a los 22 años junto con su esposa y sus cuatro hijos - todos pequeños- a una casa a 30 kilómetros de la costa, y cada día se dirige a los centros turísticos a vender sus artesanías producidas por su esposa en casa o compradas a otros huicholes artesanos. En la temporada de lluvias también busca trabajo en los campos. Aunque desde hace tiempo desea regresar a su comunidad en la sierra para visitar a los suyos y hacer las mandas en los lugares sagrados, dijo encontrarse imposibilitado de tales lujos, ya que no alcanza a financiar su viaje con toda la familia, sumándose a ello la carencia de casa o terreno comunal para regresar a la sierra. Las actividades económicas ocupan a la familia entera; incluso las niñas pequeñas laboran una gran parte del día en las artesanías, y con apuros ello es apenas suficiente para sobrevivir y pagar la renta de la casa, la cual todavía se encontraba en fase de construcción. El huichol relató que su vida es difícil 
y pesarosa: sale de casa temprano en la mañana y regresa en la noche, $y$, aunado a esto, en ocaciones nada vende. Le parecía imposible ahorrar algo de dinero. Luego, está forzado a perpetuarse en estas condiciones inseguras a sí y a su familia.

Otro amigo huichol, un mará akame de la comunidad de Cebolleta (en Tateikie), está casado, tiene cinco hijos y es el pilar de su familia, la cual permanece en su comunidad de origen debido a las actividades económicas de comercio con artesanía y la curandería comercial que él realiza, así como a las ceremonias practicadas a mestizos y extranjeros fuera de la sierra (tal vez también sea administrado y explotado por los varios mestizos que se dicen discípulos suyos). Viaja casi todo el año entre Veracruz, Puebla, Ciudad de México, Guadalajara y otras grandes ciudades del país donde se puede quedar con familiares o amigos de la sierra. Siempre está a la búsqueda de sus clientes, y a veces le es difícil encontrarlos, por lo quepor lo cual se ve obligado a vender su trabajo demasiado barato. Al analizar su papel de huichol lejano a la sierra, recordamos en demasía lo que Knab llama barroco: este amigo procura ajuararse su traje festivo, repleto de decoraciones, un collar de cornamenta de venado y a veces el típico sombrero emplumado. En otras palabras, se ocupa mucho de jugar bien el papel del chaman huichol para los no-huicholes. En contraste, durante de las fiesta de Semana Santa en su comunidad en la sierra vestía con traje normal y no ostentaba su collar. Él con regularidad asiste a peregrinaciones a Wirikuta con grupos de su comunidad de origen y también regresa por periodos muy cortos a esa comunidad en la sierra, donde en seguida ocupa cargos importantes en las fiestas tradicionales. Con esto gana dinero para su hermano menor, quien estudia derecho en Puebla. Este último dejó ya de utilizar el traje, y para ayudarse económicamente trabaja las artesanías que vende a amigos, y en el mercado del Callejón de los sapos en Puebla, durante los fines de semana. Él, por su parte, critica las actividades de su hermano mayor porque, según dijo, es falta de respeto "que vende las tradiciones".

\section{Emigración y continuidad cultural}

Con respecto a la relación entre el fenómeno de la migración y la continuidad cultural existen diferentes ideas y teorías. Por la parte de la tradición culturalista, la emigración en muchos casos ha sido vista como una fuerza de aculturación, lo cual es un peligro para la persistencia y reproducción de las culturas tradicionales. Este argumento se base en una simple hipótesis: que los emigrantes se asimilan (por fuerza o por voluntad propia) a las sociedades en las que ingresan, y en ese proceso pierden o rechazan su cultura original. También está basada en la observación de que el estilo de vida cambia mucho al abandonar la así conceptuada tierra materna, por la integración del hombre tradicional a los modernos sistemas económicos. Se presume que las gestaciones tradicionales cotidianas, como los rituales, experimentan un cambio radical, cuando no se suprimen totalmente. En cuanto al discurso político, el resultado deseado de la asimilación del emigrante a su nuevo ambiente sociocultural sería su transformación en miembro de la nueva sociedad; no obstante, en ese mismo discurso los emigrantes suelen ser presentados como desorientados, desarraigados, básicamente como individuos con déficit y problemas en lugar de cualidades. Esta concepción éademás se refleja en la literatura antropológica sobre los huicholes: la emigración es tratada como un fenómeno periférico, y las arenas y actores de la reproducción cultural son reducidos a los tradicionales (las comunidades de la sierra, las peregrinaciones, los rituales, las actividades de los marákate, etcétera). Así, no nos debe sorprender que encontremos en casi todos los autores, post-preocupaciones sobre la continuidad sociocultural huichola.

Pero en otros trabajos antropológicos hemos hallado un enfoque distinto (Lumholtz, 1904; Neurath, 2002; Knab, 2004). La investigación empírica representa a los huicholes como grupos sociales y culturales; ella contesta a la hipótesis de la desaparición del indígena/ emigrante en su nuevo ámbito sociocultural. Manifiesta que en lugar de negar y suspender las tradiciones y cos- 
tumbres, los emigrantes juegan un rol muy importante en la reafirmación y reanimación de la cultura wixarika. En lo siguiente, vamos a presentar varias prácticas de los emigrantes, las que ilustran cómo fuera de la sierra la identidad huichola se ve afirmada y con fuerza articulada frente a frente con el otro.

\section{Practicas de identidad de los emigrantes huicholes}

Dada la diferencia de las prácticas, habremos de distinguir a lo menos dos grupos: por una parte las comunidades huicholas que se establecieron fuera de la sierra, tanto en la región del Río Lerma de Santiago (desde del principio del siglo pasado y antes aun), así como las de Tepic; por otra partelos "Huicholes urbanos". En la región Santiago, los huicholes usualmente están ocupados en los campos agrícolas y aparte trabajan la artesanía que venden, igual que sus servicios de curandería a los turistas de la costa de Nayarit (encontramos un caso descrito por Knab, 2004). Muchos de los emigrantes se establecieron en comunidades huicholas, en vecindarios que en muchos aspectos procuran y se guardan de imitar la vida de la sierra en su nuevo ambiente. Allí encontramos muchos elementos socioculturales muy parecidos a los acaecidos en la vida serrana. En contraste, los "huicholes urbanos" por lo general no se encuentran apoyados por una comunidad wixarika, y en varios casos apremian en desentenderse de ella; pese a que los lazos familiares y las amistades forman una base social harto importante, en las urbes se organizan más en familias nucleares. En seguida, se presentan algunos aspectos de la vida de los dos diferentes grupos de emigrantes y sus prácticas de identidad, que aunque son parecidas en el sentido de la reafirmación en la identidad indígena frente al otro, se distinguen por sus diferentes estilos de vida.

\section{Las comunidades huicholas fuera de la sierra}

Salomón Nahmad Sittón realizó estudios entre las comunidades huicholas de la región de Santiago en
Nayarit. En ésta se establecieron asentamientos huicholes desde la invasión española en 1530. Pero fue hasta la década de los 30 del s. XX que llegaron muchos refugiados de la sierra huyendo de la violenta revuelta cristera. Según Peter Furst:

A lo largo del río Grande de Santiago, los refugiados establecieron pequeños poblados agrícolas y ejidos, continuaron llevando, tanto como les fue posible, tradicionales vidas huicholas; aunque obviamente sin el encarecido beneficio de las organizaciones del templo tradicional y la amplitud comunal de ceremonias durante todo el año en la sierra (Furst, 1996: 174)

Mucho de lo que no encontraron lo establecieron en los siguientes años. Nahmad Sittón mostró que en lugar de perder su identidad wixarika y su vida tradicional social-ceremonial, los miles de refugiados mantuvieron relaciones con sus familiares en la sierra, regresando a sus lugares de origen, hasta que establecieron templos tradicionales en sus nuevas comunidades, donde se concentra la vida comunal y ritual (Nahmad, 1996: 493) (Figura 4).

Obsérvese a Tepic, por ejemplo. Hay ahí hoy día una considerable colonia de puros Huicholes, como se llaman a sí mismos, y ellos preseveran tan fuerte como pueden en sus fiestas y ceremonias. Incluso poseen su propio tuki (Ibidem, 1996: 493).

Cuando, según él, las comunidades de la sierra se abren más y más para el mundo exterior, para las comunidades fuera de la sierra resulta visible una tendencia contraria. El autor argumenta que,

Ésa ha sido su salvaguarda como huicholes, este aislarse a sí mismos de los forasteros y resistir su influencia. Es irónico que esas personas viviendo fuera del territorio tradicional hayan debido proteger sus creencias, rituales y modos de vida más afianzadamente que sus parientes en la sierra (Ibid., 1996: 492). 
Pero parece que sacraliza veladamente el estereotipo del huichol sólo contrael mundo, cuando sin reservas varios indígenas deciden abandonar sus tradiciones.

El libro de Timothy Knab, Mad Jesus, presenta a un huichol que huyó de la sierra, quien jugó un papel fundacional en la organización de varios grupos de huicholes viviendo en, y alrededor de San Blas, Nayarit, y en la Ciudad de México. Por un lado, el libro refleja muy bien la idea que articula Nahmad Sittón, del fenómeno de los emigrantes huicholes volviéndose más a sus costumbres fuera de la sierra (Nahmad Sittón, 1996: 494). Mad Jesus, el protagonista de la etnografía de Knab, siguió practicando muchos elementos de la cultura huichola tradicional como la curandería, la producción de artesanías y ofrendas, el canto y los ritos relacionados con la deidad del mar cuyo lugar de culto, como ya dijimos, se encuentra cerca de San Blas. Amén, organizó a los inmigrantes huicholes en los aspectos económico, social y ritual. Estableció un grupo en torno al trabajo de artesanías para el mercado turístico, construyó un shiriki (o altar huichol) en el rancho donde vivieron y coordinó fiestas y ceremonias huicholas, al igual que peregrinaciones al recinto donde mora la diosa de los mares. Nos cuenta:

Seríamos más Wishalika de lo que ellos eran en la sierra.

Decidí construir un shiriki; pensamos en tal vez hasta construir un tuki. Yo era ahí el mara'kame, así que organizamos nuestros propios festivales (Knab, 2004: 158).

Si por un lado del citado discurso, la historia de Madjesus, muestra una enorme preocupación e identificación con la cultura huichola y la vida comunitaria tradicional, por otro lado, nos revela del mismo modo que tal costumbre puede menguar en muchos aspectos. El libro también nos habla del establecimiento de estructuras de poder dictatoriales en arenas de vida comunal y ritual, así como de la ebullición de nuevos cultos entre emigrantes, los cuales representan sincretismos de los cultos tradicionales de los huicholes con varias influencias ajenas (Knab: 171).
De este caso es de notar que la emigración definitiva fuera de la sierra no implica automáticamente un cambió radical o la pérdida de la cultura wixarika y de los principios de la organización comunitaria. Aunque la vida cotidiana como ritual, experimenta varios cambios, muchos huicholes que se establecieron al rededor de la costa de Nayarit y en Tepic, siguen siendo huicholes: mantienen lazos emocionales y familiares muy fuertes con sus comunidades de origen y con su vida cotidiana y ritual; he ahí su registrable continuidad a lo largo de la república. Desde la organización de la tierra hasta la vida ceremonial, son de observar los paralelos con su vida anterior en la sierra.

\section{Los huicholes urbanos}

Carl Lumholz, en su obra clásica y referente obligado sobre los huicholes, ya conocía a "Huicholes urbanos", huicholes que emigraron temporal o definitivamente a los centros urbanos del país. Uno puede creer que se asimilaron, que se perdieron en la gran mélange de los urbanos en el México post-revolucionario. Lo cual talvez fue válido para la primera generación, cuyas oportunidades de trabajo dependieron mucho de no ser identificada como indígena (Knab, 2004: 136s). Sin embargo, tal criterio parece ser estrictamente inaplicable para los Huicholes urbanos contemporáneos. No pretendemos que todo lo que parece huichol sea huichol. Cabe la probabilidad de que a veces haya una farsa de la identidad huichola, un disfraz que sea también una exitosa estrategia para vender artesanías y servicios espirituales (véanse los comentarios de Weigand sobre los huicholes profesionales, 1992: 169). Pero investigaciones actuales discuten que en muchos casos el Huichol urbano es más huichol que urbano; lo cual también colinda un poco con los juicios (icon el dogma cientificista?).

He estado convencido largo ha de que ésta es, en cualquier evento, una categoría falsa, dado que todo 
lo "urbano" en ellos radica en que hacen sus vidas en ambientes urbanos, pero como Huicholes y no cual gente aculturada o incluso aculturante tratando de devenir mestiza (Nahmad Sittón, 1996: 493).

Es obvio que estos esquemas tienen sus reveses. ¿No resulta acaso más cómodo para los no huicholes verlos como el otro y perenne extraño, inmutable cual tarjeta postal? $?^{5}$

Entonces, ¿quiénes son los huicholes "urbanos", cómo viven y qué relación tienen con las comunidades en la sierra y su cultura? Phil Weigand nos ofrece un aviso importante con respecto a los huicholes urbanos cuando dice que "el que realiza sus investigaciones en el ambiente urbano ya se está enfrentado a un enigma indescifrable, pero es una combinación muy original, dinámica e interesante" (Weigand, 1992: 171).

Como sea, nos parece insuficiente deconstruir la categoría del "Huichol urbano" para encontrarnos luego en medio del enigma, frente a una quimera que ya nada exprese (lejana a todo referente real). En lugar de ello, proponemos aquí dar cabida al próximo paso y discutir algunos elementos comunes de los huicholes que habitan en las urbes. En general, la literatura contemporánea refleja que muchos huicholes que se asientan temporal o en forma definitiva en los centros urbanos continúan siendo huicholes. Este "ser huichol" es muy diverso y tiene formas muy distintas que las habidas en las comunidades. Pero, en esencia, lo valioso radica en percibir que todavía se identifican como huicholes, en que esta identidad étnica se les presenta como una parte constitutiva de su identidad tanto personal como colectiva.

La literatura antropológica que nos habla de los "Huicholes urbanos" contemporáneos muestra que no nos referimos a individuos establecidos solos y hacinados en los centros urbanos de México, sino a conjuntos de huicholes, sean familias nucleares, conjuntos de familiares (en su sentido amplio, como lo construyen los huicholes cual contingente étnico) o grupos que se organizan según nuevos lazos económicos o emocionales. Aquí vemos una primera característica: no son individuos solos que se ganan la vida en las ciudades. Más bien, los huicholes urbanos forman redes de apoyo que les sirven como base y seguridad a sus propósitos. La base de estas fuertes redes sociales yace en muchos casos, ser miembros del mismo grupo étnico, aunque también se hace notoria la solidaridad, y la identificación con la comunidad de origen, que es más el principio de solidaridad en la sierra. Estos grupos solidarios representan el ámbito en que se reproducen muchos elementos de la cultura huichola, tanto con respecto a la organización social, como a los elementos de la vida ceremonial (tienen sus shirikis, sus tukis, van a peregrinaciones, a nuevos lugares tradicionales de culto; a fiestas en la sierra, hacen ofrendas, practican la curandería y el canto, etcétera) (Cfr. Knab, 2004; Furst, 1996; Medina, 1996; Nahmad, 1996 y Torres, 2000).

Otro campo que parece importante para la reproducción cultural en el ámbito urbano es el trabajo. Muchos emigrantes huicholes sobreviven de la artesanía y de la curandería comercial. Aunque estamos de acuerdo en que lo que están produciendo y vendiendo como "cultura huichola" no necesariamente es la cultura huichola: la demanda de la sociedad mestiza y de los turistas favorece la continuación cultural por la estimulación de la producción de artesanías y el aprendizaje, y práctica de la curandería, del canto y otras técnicas espirituales. ${ }^{6}$ Por la profunda significación y el sentido que tiene el proceso de esta producción como objetode-la-representación-artística-huichola, se reproducen contenidos centrales de la cultura wixarika, pero también y como desde siempre mutan. Aparte de las técnicas, también se transmiten los cantos (basados en cuentos, mitos y cultos en forma de tradición oral), lo mismo que conocimientos sobre el medioambiente, paisajes sagrados y la cosmovisión wixarika: por ser los dispositivos de las motivaciones en las expresiones artísticas. La apreciación de la artesanía huichola por el mundo externo también estimula indirectamente, el culto al peyote y a la tradición de soñar (y su glo- 
balización, por decir lo menos o utilizar eufemismos), puesto que las alucinaciones son la fuente tradicional de los motivos representados en el arte huichol. Su ocupación como artistas y curanderos también permite, si no es que refuerza, la aparición óptica de los huicholes como miembros de una cultura (Weigand, 1996) y así se disponen, sin duda alguna, como miembros de la etnia. Mad Jesus cuenta:

Ni siquiera tienes aspecto de huichol. Pareces un "tewali". Me dijo debería yo asemejarme a un huichol en San Blas si quería hacer dinero. Los "turistas" comprarían cosas por montones de efectivo; souvenires que podrían comprar de otros Huicholes por unos pocos pesos, me explicaba, si realmente tienes pinta de huichol (Knab, 2004: 149).

Así, para Phil Weigand, la artesanía tiene un papel central en relación con la continuación de la identidad huichola de los emigrantes.

Desde el siglo XVIII, los huicholes se han mudado a los pueblos y a las ciudades de mestizos y de españoles, en la mayoría de los casos, como refugiados políticos de las comunidades. En el pasado, la aceptación implicaba, en general, una asimilación de naturaleza más bien abrupta. Para la segunda generación, la lengua y la mayoría de los otros rasgos de la cultura aborigen ya se habían perdido. Este modelo de emigración urbana y de asimilación aún existe, pero se ha desarrollado una tendencia nueva importante que, de continuar, sin duda modificará por completo los antiguos patrones de adaptación urbana. Ahora las nuevas condiciones permiten y, de hecho, exigen que los indios que emigran conserven su identidad como huicholes dentro del ambiente urbano. La creciente popularidad de las artesanías hechas por huicholes (...) es la variable que permite y que requiere que los huicholes sigan siendo "indios" en las ciudades. Está surgiendo así, un nuevo huichol, un "indio profesional" (Weigand, 1992: 170).
Parece que una gran parte de los huicholes "urbanos", o mínimo los que trabajan las artesanías y curandería, van y vienen entre centros urbanos y turísticos como entre las comunidades de origen y sus nuevas casas en las urbes. Los que vacilan entre los diferentes lugares urbanos persiguen mucho las temporadas turísticas, siempre en la búsqueda de suficiente clientela. Los que van y vienen de la sierra regresan porque, por un lado, en muchos casos dependen de las artesanías producidas por sus familiares en la sierra y, por otro, porque muchos, ante todo los hombres que emigran solos, tienen su familia en la sierra, donde su manutención resulta mucho más barata que si la trajeran a las ciudades. El punto rescatable que deseamos enfocar aquí es, que muchos de los huicholes urbanos, que supuestamente son de más alto riesgo y proclividad a perder su identidad cultural, en muchos casos salvaguardan lazos fuertes con la sierra y regresan a sus lugares de origen, donde siguen siendo parte de la comunidad. Aunque por esa misma razón las relaciones se traslapan para sí y para su espacio.

La influencia de los emigrantes en las comunidades de la sierra es ambigua, y da pie al turismo "exótico". Weigand discute que:

El impacto de la popularidad de las artesanías y de los indios urbanos también se está sintiendo en las comunidades de las montañas. Me da la impresión de que la combinación de las subtradiciones de motivos, leyendas y artesanías se está produciendo mucho más rápido bajo el influjo de este estímulo. Aun el investigador que lleva a cabo trabajo de campo en las montañas tendrá que tener mucho cuidado con este proceso (Weigand, 1992: 171).

Pero eso no es todo. Hay otra dimension entre la migración y la cuestión sobre la reproducción cultural. Es evidente que los migrantes costean en gran parte las fiestas en la sierra (también la "nueva riqueza" de la ganadería juega aquí un rol nada despreciable). Bajo este 
soporte económico, la vida ceremonial florece enormemente en las comunidades tradicionales. Las fiestas en la sierra sirven de este modo al propósito de reintegración de los emigrantes a sus comunidades de origen, y al mismo tiempo representan un espacio importante de la reproducción cultural para la comunidad.

Antes de discutir las relaciones entre la emigración y la vida ritual en la sierra, nos parece relevante enfatizar la capacidad de apropiación e integración de lo externo en la cosmología huichola. Lo que es visible dentro del marco de las viejas rutas de comercio que coinciden con las rutas de peregrinaciones, parece reflejar un mecanismo más general. Cotejamos una gran capacidad de integrar nuevos espacios al territorio sagrado huichol [por ejemplo: la basílica de Guadalupe a las faldas del cerro del Tepeyac, donde otrora celebraran rituales los mexicas a propósito de su madre, la Coatlicue, en su advocación de Tonantzin-nuestramamacita, en náhuatl-; con el trasfondo semántico que para los hablantes de esta lengua utoazteca significa], tanto en el sentidogeográfico como con referencia a la cosmovisión. Neurath desarolló ese punto de gran importancia:

(L)os mará akate descubren nuevos lugares sagrados en los alrededores de los centros urbanos y turísticos donde los Huicholes suelen vender artesanías (Neurath, 2002: 80).

Muchas veces la emigración equivale a una expansión del territorio comunal. La fundación de nuevas comunidades crea la necesidad de organizarse nuevos centros ceremoniales. Paralelamente "descubrimientos" recientes de lugares sagrados por parte de los chamanes huicholes abren nuevos horizontes a la "geografía ritual". Entre los lugares sagrados de los huicholes actualmente se encuentran las ruinas de Teotihuacan, el Museo Nacional de Antropología, una piedra en las faldas de volcán Iztaccíhuatl y otras en los alrededores de Tepoztlán, así como la roca con petrograbados que asemeja a un águila en las Guitarritas, Nuevo León (Neurath, 2002: 26).
Así la situación, los emigrantes huicholes no se encuentran tanto all afuera, sino que se mueven en el territorio huichol; aunque emigren se postulan como in situ. Además, devienen agentes de la integración de los diferentes lugares religiosos (nuevos y viejos) en la cosmología huichola que, tanto como su territorio habitado que por tradición, se extienden con frecuencia al ritmo de sus nuevas menesterosidades y restricciones. Sólo por dar un ejemplo contemporáneo acerca de la extensión del cosmos huichol, hemos visto a huicholes hacer culto y ofrendas a imágenes dentro del Museo de Antropología.

En la actualidad los emigrantes comparten el cargo/ prerrogativa de participar en la tenaz reanimación del cosmos aún por venir o producir, llevar ofrendas y celebrar rituales en sus remotos lugares del culto y en los que se incorporan; así, al mismo tiempo están integrados a la comunidad ritual huichola. Debemos ahora reflexionar un momento sobre el concepto clásico del emigrante: si es que no se encuentra dentro ni fuera del territorio religioso huichol, y si también sigue siendo activista ritual durante su migración. ¿Es luego emigrante o peregrino? ¿Está desarraigándose o florando?

\section{Emigración y la vida ritual: reproducción cultural y reintegración}

La vida ritual no sólo florece en los tukis y en centros de peregrinación fuera de la sierra sino también dentro de ella. Bajo la influencia del capital económico que fluctúa de las manos de los emigrantes hacia las comunidades en las montañas, las fiestas religiosas se desarrollan hasta volverse grandes festivales de abundancia. Weigand observó que:

Los individuos continúan invirtiendo la mayor parte de su riqueza en las posesiones tradicionales, en especialmente ganado y cuentas, pero la forma más prestigiada de invertir la riqueza sigue siendo el patrocinio de un festival de cargo. Puesto que los individuos a menudo tienen un excedente, las fiestas religiosas (...) se están 
volviendo cada vez más elaboradas y frecuentes. Está empezando a darse un renacimiento de ceremonias antiguas, casi olvidadas (...) El intenso interés y el orgullo que los Huicholes muestran ahora abiertamente hacia su cultura se está volviendo cada vez más generalizado. Muchos funcionarios del INI y los vecinos locales están sorprendidos y asustados por este aparente rejuvenecimiento de la cultura huichola (Weigand, 1992: 168).

Neurath, cuyo libro está centrado en la pregunta sobre la continuación y reproducción de la cultura huichola, discute que por medio del patrocinio de fiestas se establecen vínculos frecuentes entre los emigrantes y las comunidades de origen. Así las fiestas (primordialmente la de Semana Santa) sirven para fortificar los lazos sociales entre los serranos, los emigrantes y la cíclica reintegración de ambos a su comunidad. Pero esto apenas nos muestra un lado de la dinámica. Neurath también discute, que la "realización material [delas fiestas] depende básicamente de los recursos obtenidos fuera de la Sierra" (Neurath, 2002: 323). Luego pues, existe además una interdependencia entre los emigrantes y las comunidades montañesas, así como también con los turistas.

Ponemos énfasis en la hipótesis de Neurath, respecto a la cultura huichola, donde los rituales figuran como un universo muy importante para la reproducción cósmicocultural. Su argumentación se funda en varias teorías antropológicas, que articulan este lazo fuerte entre reproducción sociocultural y ritual, como entre los clásicos Víctor Turner, Maurice Bloch, Theodor Preuss y Arnold van Gennep. El análisis consiste básicamente en tres partes interrelacionadas. Uno: que el ritual representa un espacio de reproducción cultural por el simbolismo que implica, y entonces accede a la articulación de un orden cosmogónico integral desde el ritual mismo. El segundo aspecto estriba en que el ritual en contrastre transforma algo real y tangible; es Impacto psicológico de una experiencia liminal y Fortalecimiento de la comunidad en su igualdad, tanto como Reestablecimiento del orden cósmico concedido por este papel central con respeto a la reproducción de cultura del ritual. El tercer aspecto, que a su vez une al primero con el segundo: a través del ritual, el cosmos experimenta una renovación, tanto simbólica como práctica. En el ritual tradicional huichol encontramos tres características: el alto contenido simbólico, la experiencia de la communitas y la intensa vida comunitaria (o vivacidad), así como su función de la reproducción del cosmos.

Dada la participación de los emigrantes en los rituales de la sierra, vemos su función con respecto a una reintegración en la comunidad. Al mismo tiempo, tenemos que tomar en cuenta lo ya dicho: los ingresos como acicates de los emigrantes para mantenerse como parte de las comunidades tradicionales en la sierra, tienen un gran impacto en la vida ritual y social de dichas comunidades. La emigración, vista desde este punto, está relacionada en varios aspectos con la fructificación y expansión de la vida ritual y comunitaria en las comunidades de la sierra y fuera de ella. Debido al papel central que desempeñan los rituales para la reproducción cultural -y este argumento nos parece válido tanto para los rituales tradicionales, como para los rituales comunitarios más allá de los confines serranos-, la emigración juega un papel toral para la continuidad de la cultura huichola, lo cual tampoco significa que no se modifiquen sus patrones culturales. Esa continuidad de la vida ritual, que experimenta una gran eclosión por la emigración tanto dentro, como desde, y fuera de la sierra, es en cierto sentido una garantía para la continuidad cultural de los wixaritari, porque Cultura y Comunidad se reaniman incesantemente mediante los rituales experimentados durante la fiesta —desde cualquier perspectiva e índole.

\section{Conclusión}

La presente exposición ha intentado demostrar que el fenómeno de la emigración es en muchos aspectos una parte integral del ser huichol. En lugar de entender a los huicholes desde de sus comunidades y centros 
ceremoniales en la sierra, se han mostrado aquí, muchos aspectos de la vida huichola, la cual se entiende mejor desde las nuevas arenas de la "huicholidad". Si nos preguntamos cómo funciona la «reproducción cultural» de tales pueblos tradicionales y cómo se desarrolló una «cultura de resistencia», nos parece muy rico investigar en los espacios donde las identidades y prácticas tradicionales se frotan contra el otro, dónde entran en conflicto, y dónde entonces se ubican los discursos y prácticas de identidad. Los emigrantes huicholes, así, se mueven al enfoque de la investigación. Vimos que no existe el emigrante huichol, sino que hay muchas formas de este complejo diálogo cultural cuyas estrategias y efectos resultan ser, necesariamente, muy variados. Una perspectiva histórica abrió el justo espacio para la reflexión sobre la relación habida entre los diferentes tipos de migración huichola y las condiciones sociohistóricas conformadas por la comunidad, por el Estado y el mundo. Entcontramos que existe una interesante coherencia entre las rutas de peregrinación y las de la emigración laboral. Vimos que la mayoría de los emigrantes se mueven en tierra re-conocida. Asimismo, juegan un papel definitivo en la vida ritual: por el hecho de tomar parte en la reanimación cíclica del cosmos, a razón de las ofrendas llevadas a los centros de peregrinación fuera de la sierra y por financiar los grandes rituales en la sierra, y también por expandir el cosmos wixarika: al arraigarlo en nuevos camarines y rituales. Por tanto, son parte de la comunidad ritual: aunque se encuentren fuera de la sierra.

Con esto, exhortamos a las futuras investigaciones a dejar atrás los conceptos unívocos de Los Huicholes (sólo vistos de la sierra), de La Cultura Huichola, así con mayúsculas. iHemos escuchado a huicholes contar su vívida versión de los hechos! Arribamos a la visión de identidades postmodernas y postmetafísicas, a frescas nociones de comunidad étnica, y a explicaciones de la resistencia cultural mediante una elasticidad practicada por sus miembros. Mostramos que la migración de la sierra tiene un impacto fuerte en la cultura wixarika, no sólo de hoy sino también del pasado. Y es que la cultura y la comunidad wixarika siguen emergiendo en la búsqueda de una base para vivir, de una identidad y de un lugar en el mundo. Apuntamos: la integración creativa de novedosos aspectos es parte de la realidad del emigrante, culmina en una identidad wixarika que se muestra fortalecida y resistiva. Entonces, en lugar de negarles a los emigrantes su autenticidad cultural, habremos de otear a estos otros quienes son verdaderamente los actores de la globalización, tanto como reproductores de la cultura tradicional.

Se agradece a los entrevistados, al Departamento de Antropología de la UDLAP y a su cuerpo docente, a las autoridades tradicionales de San Andrés Cohamiata.

\section{Notas}

${ }^{1}$ http://cdi.gob.mx/index.php?id_seccion=561.

${ }^{2}$ Todas las traducciones son nuestras.

${ }^{3}$ Cabe destacar que el precio de las artesanías se eleva en la medida en que la compra-venta se aleja de la sierra; si bien tales criterios son arbitrarios. Asimismo, varios artesanos dan razón de la procedencia de las chaquiras (elemento cardinal para elaborar sus trabajos) como importaciones de Francia, Japón y China.

${ }^{4}$ En nuestra experiencia personal y la de algunos "huicholeros" (visitantes y adeptos a las comunidades, en palabras de los propios huicholes), no es exacta esta afirmación del señor Neurath, dado que: 1 se nos han realizado "limpias" en la sierra (incluso se nos ha invitado con frecuencia a las peregrinaciones a Wirikuta con objeto de financiar parte del trayecto) y; 2: los precios varían dependiendo del juicio que cada maráakame adopte con respecto a los interesados, ya sean mestizos o indígenas (por motivos de "praestigium": ardid o apariencia, socioeconómicos, de nacionalidad, etcétera).

${ }^{5}$ Una disyuntiva hace las veces de desafío: io nos conformamos con la univocidad y el cuento de hadas, o nos abrimos a lo disperso (con el riesgo latente de no retornar a nuestro sitio, de no volver a ser nosotros mismos?). 
Con todo el riezgo, no se puede, a todo esto, revolotear, permanecer a medias tintas sobre determinados asuntos. Queda recuperar algo de estas culturas, pero partiendo de que muchas veces se hallan fuera de sus órbitas, oscilan en derredor de varios centros y penden de una interculturalidad de redes y remaches políticos, sociales y semánticos ajenos a sus organizaciones tradicionales. Resta la adaptación tanto de los receptores o culturas anfitrionas como de los emigrantes o culturas subalternas-huéspedes; aunque algunas realidades de común - retan, parodian y hasta rebasan a la teoría y a la ciencia ficción (ni hegemonía de lo mexicano ni superego acabado del otro hospedado; si bien el proceso de asimilación no necesariamente acultura, y como muestra están estos huicholes). Las identidades de las culturas locales, por un decir, se lanzan, catapultan, entreveran. La "norma" occidental (antes dominante) ya no se domina ni a sí misma y, harta de sí, ansiosa está de abrazarse sin más a lo extraño, a esas culturas alternas y aleatorias (orientalización). El proceso de socialización ahora se desarrolla más hacia el borde de estos neo-géneros de clanes (minúsculos grupos identitarios, incluso exacerbados: Michel Maffesoli), que hacia la recolección y permanencia de las culturas modélicas e ideas del Id como lo habíamos venido comprendiendo. Quizá sea sólo el efecto compensatorio de la globalización; lo que sí puede predicarse de la emergencia de este tipos de sociedades es que la cultura de la razón, el valor del trabajo por el trabajo en sí y la fe ciega en el porvenir (vectores de la modernidad), caducaron. Para dar paso a un culto al arte y la existencia, a las actividades 'creativas' y el new age. Aunque el vacío y la violencia continúan, a pesar de que la imaginación y la presencia (transmigradas) vengan y nos reclamen sus espacios.

${ }^{6}$ Tenemos noción de mutaciones que ha sufrido la artesanía por el mercantilismo, e.g., los estampados pueden variar por pedido del comprador; o está el caso sobre los trajes tradicionales, que pueden llegar a rondar los veinte mil pesos mexicanos, mientras que en Hong Kong se consiguen reproducciones por cien dólares.
7 Todos los términos anteriores han sido tomados de Neurath 2002.

8 Tomado de Knab 2004.

\section{Glosario}

Ikú, maxa y híkuri: maíz, venado y peyote: altísima trinidad en la teogonía huichola.

Haramara: principio femenino: madre de las aguas, océanos y lluvias.

Wirikuta: el desierto de San Luís representa el centro y origen del mundo y significa algo así como "lugar del cielo donde habita la flor del divino luminoso".

Teiwari: vecino, mestizo, no-indígena, gusano.

Tuapuritari: santacatarinos, huicholes de Tuapari.

Tuki: templo grande de planta circular u ovalada.

Shiriki: huichol shrine for the gods and ancestors pertaining to particular families.

Maráakame, mará akate:" "soñador”, chamán, curandero, jicarero, cantador.

Wishalica ${ }^{8}$ : huichol term for "The People", huichols. En español: wixarika.

\section{Bibliografía}

Anguiano, Marina y Furst, Peter T. (comp.) (1978), La endoculturación entre los huicholes, México, D.F.: INI.

Bloch, Maurice y Perry, Jonathan (eds.) (1982), Death and the Regeneration of Life, Nueva York: Cambridge University Press.

Bloch, Maurice (1992), Prey into Hunter. The Politics of Ritual Experience, Nueva York: Cambridge University Press.

Franz, Allan R. (1996), Huichol Ethnohistory: The View from Zacatecas, in Schaefer, Stacy B. and Furst, Peter T. (eds.) (1996), Peyote people. Huichol Indian History, Religion, \& Survival, Albuquerque: University of New Mexico Press.

Jáuregui, Jesús y Neurath, Johannes (eds.) (2003), Flechadores de estrellas. Nuevals aportaciones a la etnología de coras y huicholes, México, D.F.: INAH. 
Knab, Timothy J. (2004), Mad Jesus: The final Testament of a Huichol Indian from northern Mexico, Albuquerque: University of New Mexico Press.

Liffman, Paul (2000), Gourdvines, Fires and Wixárika Territoriality. Journal of the Southwest, vol. 42, núm.l,pp. 129-165, (cuadro).

Lumholtz, Carl (1904), El México desconocido, traducción por Dávalos, Balbino, 2 volúmenes, tomo 1, Nueva York: Charles Scribner's and Sons.

Martínez, Nova, Carmen (2004), "The Making of Vulnerabilities: Indigenous Day Labourers in mexicos neoliberal Agriculture", en Identities: Global Studies in Culture and Power, vol.1l, núm. 2, Philadelphia: Routledge, p.p. 215-239.

Medina, Silva, Ramón (1996), "How one goes to be Huichol...", en Schaefer, Stacy B. and Furst, Peter T., eds. (1996), Peyote people. Huichol Indian History, Religion, e Survival, Albuquerque: University of New Mexico Press, pp. 169-205.

Nahmad Sittón, Salomón (1996), "Huichol Religion and the Mexican State. Reflections on Ethnocide and Cultural Survival, traducción por Bonnie Glass-Coffin", en Schaefer, Stacy B. and Furst, Peter T. (eds.) (1996), Peyote people. Huichol Indian History, Religion, e Survival, Albuquerque: University of New Mexico Press, p. 468-502.

Neurath, Johannes (2002), Las fiestas de la casa grande, México: INAH-CONACULTA.

Reed, Karen Barbara (1972), El INI y los huicholes, México: INI-SEP.
Rojas, Beatriz (1993), Los huicholes en la historia, México: INI. Schaefer, Stracy B. and Peter T. Furst (eds.) (1996), People of the Peyote, Huichol Indian History, Religion e Survival, Albuquerque: University of New Mexico Press.

Torres, Jesús de Jesús (2000), El hostigamiento a "el costumbre" huichol. Los procesos de hibridación social, Zamora: Colegio de Michoacán.

Turner, Victor W. (1969), The Ritual Process. Structure and Anti-Structure, Chicago: Aldine Press.

Van Gennep, Arnold (2005) [1909], Übergangsriten, Frankfurt: Campus Verlag.

Weigand, Phil C. (1992), Ensayos sobre el gran nayar: Entre coras, huicholes y tepehuanos, México: Centro de Estudios Mexicanos y Centroamericanos de la Embajada de Francia en Mexico.

Información general sobre emigración de pueblos indígenas: http://www.senado.gob.mx/comisiones/directorio/indigenas/assets/docs/informacion/migracion. pdf y http://cdi.gob.mx.

\section{Lista de Figuras}

Figura l: El territorio Wirikuta, elaborado por Susan Alta Martin, tomado de Liffmann, 2000:130.

Figura 2: "Huichol artis, Luciano Valdez and Huichol Shaman Marcelino, shopping at the target near Gathering Tribes, December 2005" (http://www.gatheringtribes.de/photoalbum.php?go=view\&picid=40).

Figura 3 (tomado de http://www.nierica.com).

Figura 4 (tomado de Nahmad Sittón, 1996: 493). 


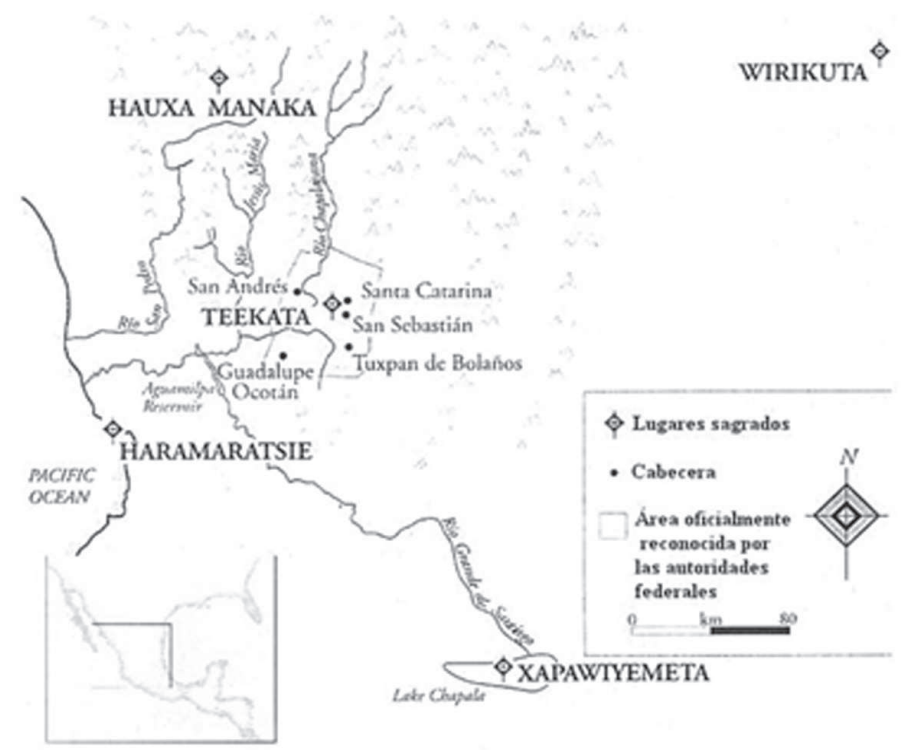

Figura 1. El territorio Wirikuta, elaborado por Susan Alta Martin, tomado de Liffmann, 2000:130

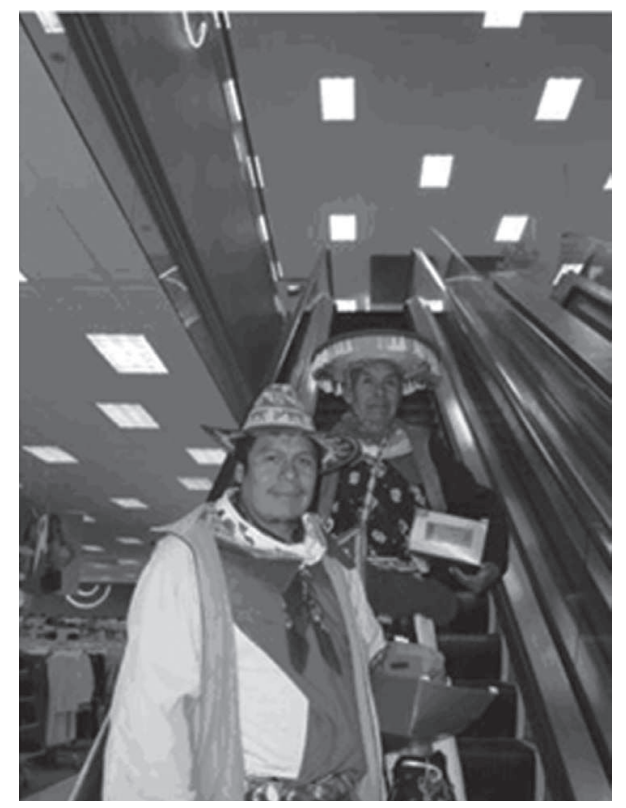

Figura 2. "Huichol artis, Luciano Valdez and Huichol Shaman Marcelino, shopping at the target near Gathering Tribes, December 2005" (http://www.gatheringtribes.de/photoalbum.php?go=view\&picid=40) 


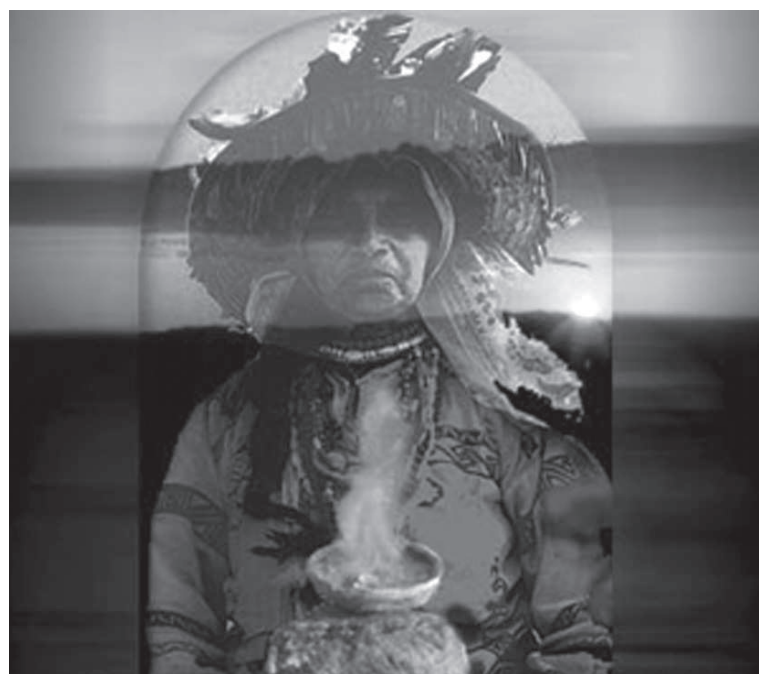

Figura 3. (tomado de http://www.nierica.com)

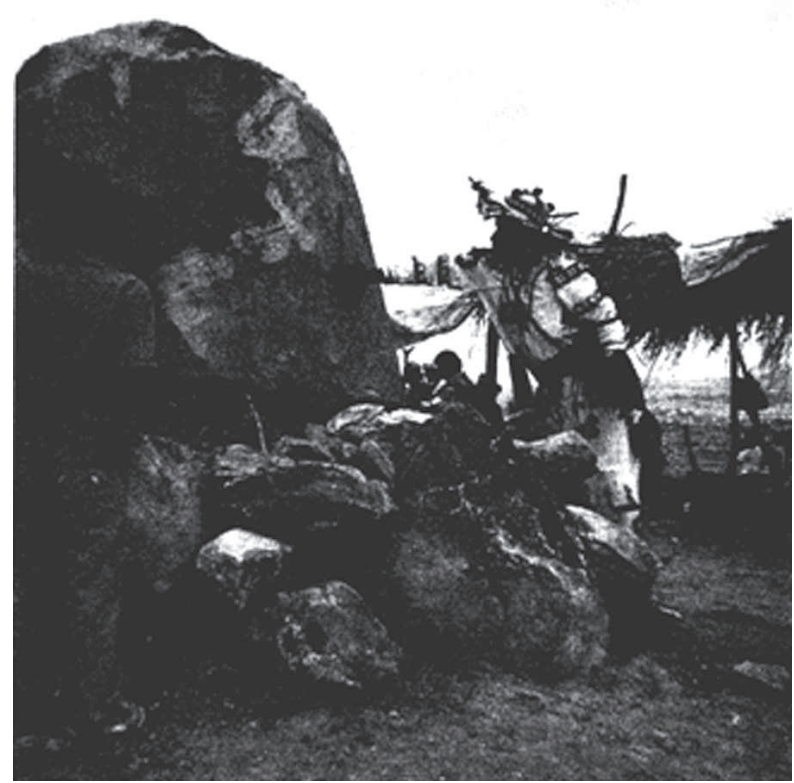

Figura 4. (tomado de Nahmad Sittón, 1996: 493) 